\title{
Three Empirical Strategies for Teaching Statistics
}

\author{
Stephen M. Marson
}

\section{INTRODUCTION}

It should come as no surprise that the statistics course is the most dreaded part of the curriculum for social work majors. Research supports this observation (Forte, 1995; Wilson \& Rosenthal, 1992; Royse \& Rompf,1992). The question is, "Can the statistics course be made less dreaded?" If statistics can be taught in a less dreaded manner, students who complete the course may actually apply statistical concepts in their practice and thus advance the profession. The corollary to the question is, "If it is possible to make the course less dreaded (perhaps even enjoyable), will students learn what they need to know?"

Research demonstrates that anxiety can be reduced by not having students learn the material (Wilson \& Rosenthal, 1992). However, can a course be designed that is more palatable, but also provides a structure in which social work students can learn what they need to know? The literature suggests two critical aspects regarding the learning of statistics that may be fruitful:

- Giraud (1997) reports that students learn statistics better in a noncompetitive classroom environment. Giraud used an experimental design which demonstrated that the group with less grade pressure received statistically significant higher test scores on their statistics quizzes. Statistics is highly intimidating for BSW students. Making the course less competitive should prove to benefit students.

- Historically, statistics professors are beginning to admit that they have made the course much more complicated than it needs to be (Yilmaz, 1996). For example, Stuart (1995) notes that introduction to statistics courses have been traditionally based on "mathematical requirements." This is based on the premise that "the necessary mathematics must be in place before any real applications can be discussed." He argues that, "not only is this unnecessary, it is counterproductive for most students" (p. 45). In her research, Coulter (1995) notes that de-

emphasizing mathematics provided a positive learning experience for students.

A synthesis of research and over eight years of teaching Social Statistics by the author suggests that a statistics course can be offered that will not be dreaded but will be an open mind to learn. In addition, and equally important, social work majors can enhance their statistical competency and use what they learn to effectively assess their practice and to advance the profession. Three empirically supported teaching strategies can be applied to a statistics course that will enhance learning. These are:

- feedback of correct answers immediately following each quiz;

- use of original data collected and analyzed by students; and

- repetition of statistical concepts using a variety of tactics.

Each empirically supported strategy is addressed by a brief review of literature, a description of how the strategy was employed in the classroom, and anonymous students' evaluative comments which assess the effectiveness of the strategy. 


\section{IMMEDIATE FEEDBACK}

\section{The Literature}

"Immediate feedback" is the concept employed in social learning theory and education to describe the process by which an organism is given a correct response after an error. The classic literature is clear. For example, Houston (1981) speaks of a "delay of reinforcement gradient," suggesting effectiveness of feedback/reinforcement decreases with increasing delay. Marx (1970) points out that the general principle is that delay of feedback (reinforcement) following a response leads to decreased rates of responding in operant learning situations. However, more recent literature on immediate feedback is quite conflictual and contradictory (Bjork \& Bjork, 1996; Gagne, 1970; Jahnke \& Nowaczyk, 1995; Kintsch, 1998). For example, Portier and Galen (1992) illustrates that immediate feedback is less effective than postponed feedback while Mason and Redmon (1992) demonstrate the exact opposite in their research.

As students become involved in any kind of learning enterprise, they are constantly receiving stimuli that indicate how they are progressing. Behavioralists and educators use the term "feedback" to describe this special kind of stimuli in response to correct or incorrect answers. The amount and timing of this feedback has an influence on the capacity to internalize information [see Hill (1981) for detailed discussion of feedback]. Bilodeau (1966) noted that feedback is probably one of the most critical variables affecting knowledge/skill acquisition. Within the context of this paper, feedback refers to the timing in which a correction is given to a student. Although the recent literature is conflictual, it can probably be assumed that the more quickly students correct their errors, the more likely that they will learn from their mistakes.

\section{The Application}

The question becomes, "Does giving immediate feedback on quizzes help students learn statistics?" In the course taught by the researcher (SWK 360 Social Statistics) students are given five quizzes per semester. Unlike traditional quizzes, these five tests are made up of multiple choice questions. Multiple choice questions have the advantage of requiring students to employ their statistical knowledge to solve problems (like the more traditional exams), and also are quicker to grade. After each (open-book, open notes, and use of calculator) exam, each student meets with the professor to have the exam graded and scored. Upon receiving the corrections, students are given the homework assignment to retrace their steps and write an essay correcting their errors.

With the correct answers, student work out their calculations "backwards." That is, starting with the correct answer, they can assess the process of getting the correct answer. Students have a weekend to complete the project. In more recent years (based on the literature), they have been encouraged to complete this task in study groups. Upon completing the homework successfully, they are given half credit for each correction. Thus, if there are 30 items on the quiz, each item is worth 3.33. When a student successfully corrects an item, it is scored to receive 1.67. The multiple choice items cannot be described easy; the average (mean) usually hovers around 55\%. The test items address application of statistics. Students never seem to realize that the correct answer cannot be found in the book. If a student cannot derive the correct answer alone or in a study group, the professor and student work out the problem together and the student receives a quarter $(1 / 4)$ credit for the effort. 


\section{Student Evaluations}

Following are unedited, anonymous, student evaluative comments regarding the value of immediate feedback (summer, 2004).

- Feedback also helped to learn and understand material

- the feedback on the exams is an excellent idea because it helps the students that doesn't catch on in class as quickly.

- The feedback after the exams were great because it allows me to know exactly what I missed and why went wrong.

- helped to correct exams

- Dr. Marson gave feedback in a quick and effective manner

- I like the individual help on feedback on the test. If something is unclear I can immediately see why I missed the questions.

- immediate feedback from exams

- The exams were hard but fair I like the ability to correct the test.

- Feedback on exams extremely helpful.

- I really did like the way we got our test back immediately \& then worked the problems out we got wrong.

- It was great to get the feedback from the exams with a chance to better your score by corrections and it was helpful in learning.

Of the three teaching strategies, immediate feedback received the highest praise. One could hypothesize that a student becomes intellectually enriched by the experience of comprehending errors. One also could hypothesize that immediate feedback received highest praise because this strategy improved one's grade. The third hypothesis includes a combination of being intellectually enriched and increasing one's grade. The author's personal observations indicate a negative linear relationship. As students progress through the semester, intellectual enrichment decreases while the lust for a high grade increases.

\section{REPETITION}

\section{The Literature}

Like the literature addressing immediate feedback, the material on the learning consequences of repetition is quite conflictual and contradictory (Campbell \& Proctor, 1993; Carr, Brown, \& Charalambous, 1989; Goshen-Gottstein \& Moscovitch. 1995; Kiewra, Mayer, \& Christensen, 1991; Kirsner \& Speelman, 1996). However, three facts exist on which there is great consensus among scholars.

1. Repetition unambiguously aids in enhancing short-term memory particularly in the ability to recall steps or stages-known as "serial recall" (Henson, 1998). Thus, repetition may be a key aspect of retaining new knowledge. In learning statistics, formulas are BEST taught and understood in steps or stages. Clearly, the research on repetition demonstrates that repeating the steps in calculating a formula is very beneficial. 
2. Bentin and McCarthy (1994) demonstrate that repetition over the long haul enables a student to complete the task with less stress. Thus, having students complete different thought problems using the same formula may not be redundant; rather such homework assignments are beneficial for acquiring a depth of understanding.

3. Repetition is rarely harmful. Repeating information appears to have emotionally harmful effects for people with Organic Brain Syndrome (Spector \& Orrell, 2001). For example, nursing home social workers know that it is psychologically hurtful to repeat forgotten information to some patients. Such patients become agitated and commonly move into states of paranoia. We don't see college students with such disorders.

The three issues of consensus found in the literature on repetition are employed as a springboard for classroom learning and instruction.

\section{The Application}

The central advantage of repetition to student learning is twofold. First, repetition of complex concepts produces a greater likelihood of understanding such concepts. Second, student ability to comprehend complex material varies on strategies used to introduce the material. Some students immediately comprehend a statistical concept with one type of presentation while experiencing great difficulty with another. Thus, employing a variety of different strategies for presenting complex information increases the chances for all students to comprehend the material. Four strategies are utilized for repetition of complex, abstract or foreign statistical concepts. These include Syllabus, Text, Lectures, and Films. Each is discussed.

\section{Syllabus}

The electronic syllabus used is available on the Internet at the following URL: http://www.uncp.edu/home/marson/360.html.

As part of a standard syllabus, course objectives are listed. In developing these course objectives, careful attention is given to include key statistical concepts used in the composition of each course objective. Within each course objective, there is at least one statistical concept. Each concept is hot-linked to definition and/or example(s). Some of the more complex concepts such as "Simpson's Paradox" offer more than three examples. A painstaking effort is made to employ a variety of definitions and examples from a variety of different sources.

Text

The text used for this course is David Moore's The Basic Practice of Statistics. New York: W.H. Freeman Publishers. This text was selected for a variety of reasons. The key purpose of the adoption of this text is related to the inclusion of time-series analysis which is particularly useful for social work practitioners. Sadly, statistics texts specifically designed for social workers rarely give adequate details regarding time-series analysis even though time-series analysis is the basis for single system designs. Moore's text (and accompanying $\mathrm{CD}$ ) for non-math majors offers an introduction of key concepts that have direct application to the evaluation of entry-level generalist social work practice. 
Key statistical concepts are introduced in Moore's text in a manner that is different from the other sources of introducing the same concepts. In addition, the format of the text follows the order by which the concepts presented in the course objectives published on the syllabus. This enables the students to efficiently follow the various sources of repetition with ease.

\section{Lectures}

The lectures offered forSWK360 are similar to standard lectures that are offered in any introductory statistics course for non-math majors with one possible exception. As with the text, the lectures follow the course objectives and emphasis is placed on the statistical concepts that are housed there. Again, following the identical order enables students to efficiently follow the various sources of repetition with ease.

\section{Films}

The film series entitled Against All Odds is used as the fourth strategy of repetition. Moore (1993) rightly points out that the obvious weakness of the utilization of films in the classroom is the lack of interaction between the professor and the student. However, the use of films is an ideal and empirically supported strategy for the repetition of complex statistical concepts. Moore (1993) cites research that supports the notion that students with high visual/spatial ability comprehend complex statistical concepts better than students with weak visual/spatial ability. Thus, films are an ideal tool for repetition, but all 24 films are not normally used in a class. One basic motive for repetition is to assure that every student will be able to effectively comprehend the material at least once.

\section{Student Evaluations}

Following are unedited student evaluative comments regarding the value of repetition (summer, 2004).

Repetition was very helpful:

- The repetition of the films is helpful but sometimes they get confusing.

- The films were very useful in learning about satisfaction. I'm a visual person it was a helpful thing.

- Films were hard to understand.

- The films and his teaching style was/were [sic] useful in having an understanding of the class.

Repetition in class did help:

- The films were very well choreographed [sic] with the class.

- Film was helpful/repetition positive.

- I do feel that the repetition was helpful-the films were some helpful.

- Repitition [sic] was helpful but the course was still hard to comprehend.

When compared to the other two strategies, the effects of repetition are less clear. If a student immediately understands a new statistical concept, repeating the concept using a 
different approach may in fact be more confusing-or perhaps the student did not really comprehend in the first place? The reverse would suggest that if a student does not immediately understand a new statistical concept, repeating the concept using a different approach may elucidate. The above students' comments suggest that both have occurred.

\section{ORIGINAL DATA}

\section{The Literature}

The initial support for the use of original data comes from a Chinese proverb (Smith, 1998): "I hear, I forget. I see, I remember. I do, I understand." In addition, several authors suggest that when students work with their own data, they have a better understanding of statistical concepts:

- Thompson (1994) illustrates the successful learning from psychology students. He gives his students an instrument (Student Information Questionnaire), has them adapt it to their own college experience, and collect and analyze their own data.

- Mackisack (1994) illustrates that classes in which students employed their own data received higher test grades and gave more favorable evaluations of the dreaded statistics courses. She employs six different experiments including: pizza experiment, the skipping experiment, the swimming experiment (mentioned above), the squash ball experiment, the golf experiment, and the paper-plane experiment.

- Richardard and Haller (2002) have their students study probability with "kisses." In this case the students are given two types of Hershey Kisses. Instead of flipping coins to be introduced to the concept of probability, they tossed Kisses and constructed probability tables.

- Fillebrown (1994) uses different student-collected data for each module of her statistics course.

- "West Point adopted an elementary statistics text that uses knights, serfs, castles, lances, armor, etc., in all their problems and examples" (Grandage, 1998, personal communication).

- For example, in one class an army officer showed little interest in learning statistics until given an example of how WWII intelligence officers were able to accurately predict the number of German tanks by employing a nonparametric technique with the serial numbers collected from the field (Noether, 1976).

The central concept underlying use of original data focuses on "relationship building" in the learning process. Students learn best when they are introduced to new concepts through the use of material with which they have personal familiarity or acquaintance. Introducing familiarity with a new concept makes for a comfortable learning experience.

\section{The Application}

In SWK 360, students report to the infirmary to have a "modified physical" as part of their first homework assignment. Collecting this type of information for learning statistics is found elsewhere (Tanner \& Wardrop, 1992). The data include: height, weight, blood pressure, 
resting pulse, body fat, blood pressure, tobacco use, sex, and stress score (see Corcoran \& Fischer, 2000, pp. 376-377). Addition categorical data are required to be analyzed for the course. Thus, two additional questions are asked:

- Do you own a skirt? YES/NO

- Do you have a pierced ear? YES/NO

The data are made available to students by using the last four digits of their student ID. Identities of students are additionally hidden because students receive a dataset from two sections of the course.

The distributions of weight, height and body fat are employed to calculate and understand correlation. For understanding z-scores, normal distribution, and standard deviation, the rest of the interval data are used. For example, students calculate the z-score for their individual weight, the z-score for a given weight, and are asked to graph the space between the two z-scores on a normal distribution plot. Students learn about t-tests with two distributions of the stress test administered on the first day of class and the final week of class. For social work majors (this wasn't true for a section of nursing students), the null hypothesis was always successfully rejected for a one-tail test. The concept of students being more stressed at the end of the course becomes statistically significant. The categorical data are used for chi-square. The data used for chi-square does not elicit as high a degree of a positive learning experience as the stress test. More meaningful data are still being sought for this aspect of the course.

Using the modified physical as a springboard, students are required to collect time-series data at equal intervals. Thus, each student has personally meaningful data to assess within the context of a control chart. Students present a graphic, plot standard deviations, and write a short essay that offers some meaning for their personal dataset. In addition to using Knapp (1996) to illustrate probability theory by playing cards, each student is required to play ten games of solitaire employing Los Vegas Rules. A histogram of the winnings and losses is constructed and presented in class. The most striking learning activity is when the histograms from past classes are presented. There is a conspicuous similarity with all of the histograms (see Figure 1 as an example). The experience of seeing the pattern of nearly identical distributions elucidates the natural and unbiased effects of good data collection.

Students construct graphics to illustrate virtually all of their original data.

\section{Student Evaluations}

- Personal data is ok, the books data would have been ok

- The personal data helps in that it gets the students more involved wanting to know the results.

- The personal data was an easy way to learn and recap for the class.

- Personal data easier to understand

- The personal data made the information easier to understand and grasp

- Do believe the personal data provided in class helped much more than the textbook alone.

- I liked the use of personnel statistics

- Personal data made homework assignments more interesting, by dealing with statistical information of people we know. 
- I do not have a clear understanding of this course mathematical concepts are hard for me to grasp and I end up paying less attention in the classroom setting.

- I relate much better to personal data.

- Personal data makes it more understandable. My level of knowledge for this course is not good.

Using original data greatly helps some students while the strategy has no positive impact on others. More encouraging is that the use of original data did not frustrate or inhibit the capacity to learn.

\section{FIGURE 1 \\ Solitaire}

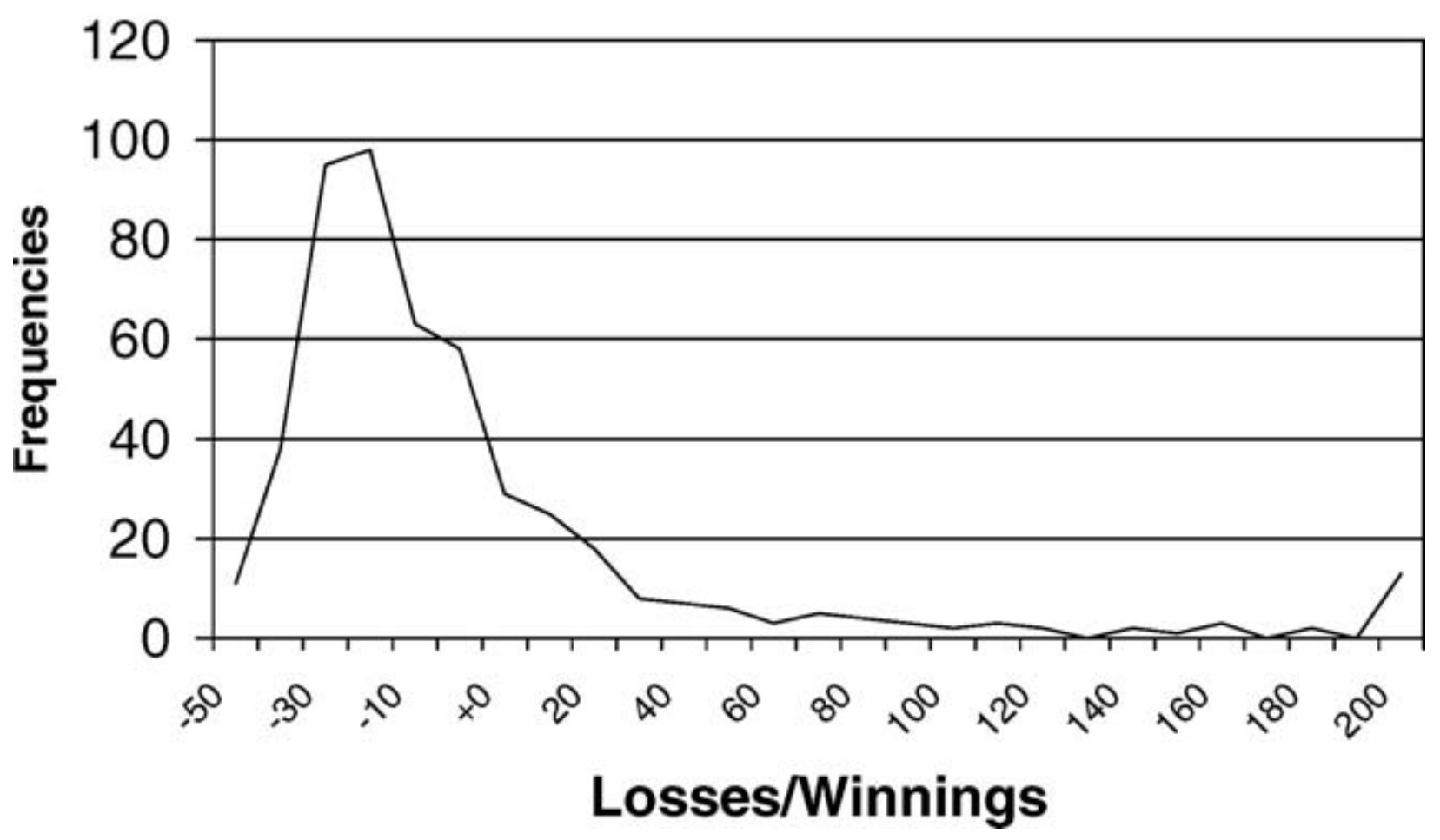

\section{SUMMARY AND RECOMMENDATIONS}

The three strategies (repetition, immediate feedback, and use of original data) all had a positive effect on learning statistics, but to different degrees. By far, the strategy that had the greatest positive impact was immediate feedback. Immediate feedback accomplished two critical learning goals. First, students were in a position to immediately see their errors and were given an opportunity to contrast their mistaken reasoning to the reasoning for getting the correct answer. Second, it reduced the pressure to learn material and the students could at work their own pace.

Repetition was also helpful despite fears of repeating too much. Yet, over the past 8 years, no student has complained about being annoyed with the constant repetition. The 
films, Against All Odds seem simplistic and well presented. Some students complain that the films too difficult to understand. Perhaps these students need additional tutoring.

The use of original data was the most complex to understand. Some students found the use of their own data helpful, while others found that they could understand just as well with the examples in the book. Possibly these later students were more mathematically inclined than the former group. The reason that some students would not like use of original data is that they are required to collect data as part of their homework-additional work to do.

\section{Strengths}

At the beginning of each class, my three teaching strategies are outlined. Students are asked to reflect on these strategies in the learning process throughout the semester. Dissent is encouraged but the students consistently indicate that the strategies constitute reasonable learning tactics. Students seem to appreciate being involved in the discussion of teaching methods. Some students seem surprised that at the concern about their learning. In addition, they like to know what is going to happen during the semester. Thus, in addition to the strategies, the students' performance may be influenced by the concern for their learning.

\section{Weaknesses}

Several points of weaknesses can be addressed:

- In using original data, the professor doesn't learn the solution to the problem until the students. Thus, this leaves no time for preparation. The professor has to be confident in dealing with students' question.

- It is difficult to detect cheating with homework. Students are encouraged to work together, but in some circumstances (i.e., looking at quiz grades) it is obvious that copying was done.

- This was not a controlled experiment. It was simple observations. The author designed a controlled experiment, but preliminary presentations suggest that it will not be approved by our Institutional Review Board (IRB).

- The high rating given by students for immediate feedback may be false. That is, some are likely to rate immediate feedback as an asset to learning because it affects their grades rather than the effects on learning.

No one doubts that statistics is the most dreaded course in the social work curriculum. However, current findings in education and statistics demonstrate that the teaching of statistics need not have this unsavory reputation. To make statistics a more palatable course, social work faculty can pursue two different avenues. First, social work faculty need to use the current literature on teaching statistics. Most of this material is not found in the social work literature, but in periodicals, such as The Journal of Teaching Statistics within this literature, one will find highly creative strategies to get students excited about learning statistics.

Second, social work faculty need to conduct controlled studies that address questions like, "What teaching strategy works best?" However, a major drawback inhibits this kind of controlled study. Campus Institutional Review Boards (IRB) are not likely to approve such designs. Essentially, a researcher would propose a theory regarding an effective teaching 
strategy. One randomly assigned group of students would be denied the innovation while other group of students would gain a theoretical learning advantage. Frankly, college students and their parents would be outraged at such a prospect. Thus, we must continue to pursue innovative teaching strategies and evaluate them by employing student evaluations that include specific questions which address a particular innovation.

Appreciation and understanding of basic statistical concepts is not an integral part of mainstream social work education and practice. When social work practitioners do not understand or appreciate the subtleties of statistical inferences contributions to the knowledge base are quite limited. In addition, the current systematic evaluation of social work practice must be called into question. If social work professors can make statistics more meaningful to larger groups of students, great advances in the knowledge base and the evaluation of social work practice are sure to follow. 


\section{REFERENCES}

Bentin, S. \& McCarthy, G. (1994). The Effects of Immediate Stimulus Repetition on Repetition on Reaction Time and Event-Related Potentials in Tasks of Different Complexity. Journal of Experimental Psychology, 20 (1), 130-149.

Bilodeau, I.M. (1966). Information feedback. In E.A. Bilodeau (ed). Conference on acquisition of skill. NY: Academic Press.

Campbell, K. C. \& Proctor, R.W. (1993). Repetition Effects With Categorizable Stimulus and Response Sets. Journal of Experimental Psychology, 19 (6) 1345-1362.

Carr, T. H. Brown, J. S. \& Charalambous, A. (1989). Repetition and Reading: Perceptual Encoding Mechanisms Are Very Abstract but Not Very Interactive. Journal Experimental Psychology, 15 (5), $763-778$.

Coulter, X. (1995). A new way of teaching statistics. Journal of Educational Technology Systems, 24 (2): 181187

Fillebrown, S. (1994). Using Projects in an Elementary Statistics Course for Non-Science Majors Journal of Statistics Education, 2 (2), https://www.amstat.org/publications/ise/v2n2/fillebrown.html

Forte, J. (1995). Teaching Statistics without Sadistics. Journal of Social Work Education, 31 (2): $204-218$.

Giraud,G. (1997). Cooperative Learning and Statistics Instruction. Journal of Statistics Education, 5 (3), https://www.amstat.org/publications/ise/v5n3/giraud.html

Goshen-Gottstein, Y. \& Moscovitch, M. (1995). Priming Effects for Newly Formed Associations Are Perceptually Based: Evidence From Shallow Encoding and Format Specificity. Journal of Experimental Psychology: Learning, Memory and Cognition, 21 (5) 1249-1262.

Henson, R. (1998). Item Repetition in Short-Term Memory: Ranschburg Repeated. Journal of Experimental Psychology, 24 (5) 1162- 1181.

Hill, W. F. (1981). Principles of Learning: A Handbook of Applications. Sherman, Oaks, CA: Alfred Publishing.

Houston, J. P. (1981). Fundamentals of learning and memory. New York: Academic Press.

Kiewra, K. A., Mayer, R. E.,\& Christensen, M. (1991). Effects of Repetition on Recall and Note-Taking: Strategies for Learning From Lectures. Journal of Educational Psychology, 83 (1), 120-

Kirsner, K. \& Speelman, C. (1996). Skill Acquisition and Repetition Priming: One Principle, Many Processes? Journal of Experimental Psychology, 22 (3), 563-575.

Knapp, T. R. (1996). Learning Statistics Through Playing Cards. Thousand Oaks, CA: Sage Publications.

Lee, C. (1999). Computer-Assisted Approach for Teaching Statistical Concepts. Computers in the Schools, 16 (1), 193-208.

Marx, M. M. (1970). Learning. London: Collier-MacMillan Limited.

Mason, M. A. \& Redmon, William K. (1993). Effects of Immediate versus Delayed Feedback on Error Detection Accuracy in a Quality Control Simulation. Journal of organizational behavior management, 13 (1): $49-83$.

Noether, G.E. (1976). Introduction to Statistics: A Nonparametric Approach. Boston: Houghton Mifflin.

Portier, S. J. \& van Galen, G. P. (1992). Immediate vs. postponed visual feedback in practising a handwriting task. Human Movement Science, 11(5): 563-592.

Richardson, M. \& Haller, S. (2002). What is the probability of a kiss? (It's not what you think). Journal of Statistics Education, 10 (3) http://www.amstat.org/publications/jse/v10n3/haller.html.

Royce, D. \& Rompt, E.L. (1992). Math anxiety: A comparison of social work and non-social work students. Journal of Social Work Education, 28 (3), 270-277.

Spector, A. \& Orrell, M. (2001). Reality orientation. In Mezey, M. (ed). The Encyclopedia of Elder Care (pp. 557-559). NY: Springer.

Stuart, M. (1995). Changing the teaching of statistics. The Statistician, 44 (1): 45-54. Wilson, W. C. \& Rosenthal, B. S. (1992). Anxiety and performance in an MSW research and statistics course. Journal of Teaching in Social Work, 6 (2): 75-85.

Yilmaz, M. R. (1996). The Challenge of Teaching Statistics to Non-Specialists. Journal of Statistics Education, 4 (1). http://www.amstat.org/publications/jse/v4n1/yilmaz.html

This is an electronic version of an article published in Journal of Teaching in Social Work, Vol. 27(3/4) 2007. Journal of Teaching in Social Work is available online at: http://www.informaworld.com doi:10.1300/J067v27n03_13). 